\title{
Interactive comment on "The promotion effect of nitrous acid on aerosol formation in wintertime Beijing: possible contribution of traffic-related emission" by Yongchun Liu et al.
}

Yongchun Liu et al.

liuyc@buct.edu.cn

Received and published: 18 May 2020

We appreciate you for your valuable comments and suggestions. We have responded to all of your comments point-by-point and have revised the manuscript accordingly. These revisions are described in the Supplement file below.

Please also note the supplement to this comment: https://www.atmos-chem-phys-discuss.net/acp-2020-150/acp-2020-150-AC1supplement.pdf 
Interactive comment 